\title{
Traceur as bricoleur. \\ Poaching public space through bricolent use of architecture and the body
}

Matthew D. Lamb

The Pennsylvania State University, United States of America

Department of Communications Arts \& Sciences

md120@psu.edu

\begin{abstract}
This paper emerged from many months of regular participation in the parkour community in Indianapolis, Indiana. First, this study looks at the art of parkour as a bricolent engagement with architecture. Acts of bricolage, a sort of artistic making-do with objects (including one's body) in the environment, play with(in) the dominant order to "manipulate the mechanisms of discipline and conform to them only in order to evade them" (de Certeau, 1984: xiv). Second, this study investigates architecture's participation in the production and maintenance of what de Certeau calls, "operational logic" (p. xi). That is, how architecture acts as a communicative mode of space; one, which conveys rationalized or acceptable ways of being in space. This critical ethnography, then, takes to task the investigation of how traceurs, the practitioners of parkour, uncover emancipatory potential in city space through bricolent use of both architecture and the body.
\end{abstract}

Keywords: public spaces system; urban design; management plan; enhancement of cultural heritage; historic urban landscape.

\section{To cite this article:}

Lamb M. D. (2017). Traceur as Bricoleur. Poaching Public Space Through Bricolent Use of Architecture and the Body. The Journal of Public Space, 2(I), 33-44, DOI: I0.5204/jps.v2il.48

This article has been peer-reviewed and accepted for publication in The Journal of Public Space. Please see the Editorial Policies under the 'About' section of the journal website for further information. 


\section{Architecture as Communicative Mode}

Movement, while seemingly a free enterprise, is very much disciplined in urban space (Mitchell, 1995). The built environment prescribes certain movements; movements centred, for example, ongoing to work, returning home, or guiding you from shop to shop. Architecture's influence on spatial modality and expected usages of space is actually part of the design strategies of architects and city planners (Gieryn, 2002). Buildings in urban environments are "designed to reflect, as well as to create patterns of behaviour" (Hiller et al, 1987: 233). In fact, architects and planners have attempted to transpose temporal social processes into spatial functions and 'fix' them within the city's structure, with the goal being a "clear definition and separation of urban environments into exclusive zone of domestic, labour, and leisure activities" (Lloyd, 2003: 95). Zoning regulations, too, can influence communication and interaction by "controlling communication activities or by controlling communication contexts" (Drucker \& Gumpert, 1991: 299). Further, as Ash Amin (2008) describes, the ordering of the built environment works to "shape public expectation, less so by forcing automatic compliance, than by tracing the boundaries of normality and aspiration in public life" (p. 15).

Moreover, architecture and urban planning often are primarily concerned with the gentrification of city space and arranging space to support the capitalist prerogatives of entertainment, production, and consumption.

Because architecture communicates codes of conduct and networks of power it shows us where we fit in, where we do not, and signify acceptable behaviour. This develops an embodied knowledge of city space (Lamb, 2104b). Architecture, then, participates in the production and reflection of the intelligibility of the body and thus subjectivity. Use of public space is deeply coded and reflects the operational logics embedded within us and within space. When we change how we use space we challenge many of the schemas and conventions on which urban space is designed and understood. By privileging certain actions architecture and the landscape of the city can become constricting and in their banality hide possibilities for alternative uses of space.

Therefore the purpose of this study is twofold. First, this study looks at the art of parkour's engagement with architecture as an act of bricolage against subjectivity. Acts of bricolage are a sort of artistic making-do with objects (including one's body) in the environment. Bricolent manoeuvres play with(in) the dominant order to "manipulate the mechanisms of discipline and conform to them only in order to evade them" (de Certeau, 1984: xiv). Second, this study investigates architecture's participation in the production and maintenance of what de Certeau calls, "operational logic" (p. xi), that is, how architecture conveys rationalised or acceptable ways of being in space, and how traceurs develop an alternative parkour vision. Using interviews conducted in the field, this participatory and critical ethnography explores how traceurs, the practitioners of parkour, uncover emancipatory potential in city space through bricolent use of both architecture and the body.

\section{Studying Parkour}

In order to understand the relationship between architecture and the body, it was important to me to be a true participant in the parkour community. I wanted to not only engage traceurs of various skill levels but also develop my skills along with them. Because of my integration into the community, I was able to conduct interviews, take field notes, 
and be an active observant participant obtaining an in-depth and situated knowledge in the art of parkour.

Throughout my time developing as a traceur and studying the art of parkour I have taken the position of the critical ethnographer. The critical ethnographic approach extends inquiry into critique. This approach allows for analysis and investigation into hidden, unrealised forms of power and assumptions that constrain and discipline everyday life (Thomas, 1993). Specifically, I have patterned my critical ethnography around Gajjala and Altman's (2006) epistemologies of doing ('Producing Cyber-selves').

An epistemology of doing is defined as the "exploration of process through doing and being self-reflexive while doing ... [it requires] the subject/object to produce selves...[and] to continually interact and 'live' at these interfaces" (Gajjala, Rybas, and Altman, 2007: 210). The doing is essential to parkour in its progression and its study. Interacting with fellow traceurs is important to the experience and learning process. However, of paramount importance in the study and understanding of this art form is the personal and corporeal engagement with architecture and the built environment.

Additionally, the critical ethnography, more specifically here an epistemology of doing, functions to abstract from my experience a way of understanding while at the same time calling attention to the positionality of the researcher-participant. While I wanted an insider's perspective my experiences as a traceur are not the only source of report or analysis. I draw from fellow traceurs' personal accounts and interpretations to build a collaborative inquiry. Thus, a participatory critical ethnography provides a more balanced understanding of traceurs' articulation of the built environment, its meaning, and their relation to it.

During the summers of $201 \mathrm{I}$ and 2012 I participated in monthly parkour jams: events organised for traceurs to gather, practice parkour, and socialise. The jams were held at various locations in downtown Indianapolis, Indiana and consisted of members of the Indianapolis parkour community. It was common for jams to average approximately I5 participants. Occasionally, jams would have as many as 50 , although very rare, and as few 3 or 4 traceurs in attendance. I took field notes during jam sessions and conducted informal interviews during breaks between runs. I spoke with 17 regular participants in formal interviews conducted at the end of several jams in the summer of 2012. I wanted my interactions with fellow traceurs to come from a place of trust, a trust established through my progression and acceptance as a traceur. The traceurs who attended had various levels of expertise ranging from novice, a beginner having only a day or maybe a month of training, to experienced or seasoned traceurs. These experienced traceurs rival the talent you would see on popular YouTube videos. I, however, fell somewhere in between.

The traceurs attending the Indianapolis jams were primarily Caucasian males and females in their late teens and early twenties. However, Asian, African American, and Latinos also attended jams with some frequency. Class distinction, too, was varied yet there seemed to be a balance in the number of participants from affluent neighbourhoods to the north and underprivileged neighbourhoods closer to the city centre. Kidder's (2012) study of Chicagoland parkour allowed traceurs to choose between using their given names or their parkour nicknames in recording the interviews. I found this to be helpful and offered participants here the same option. I found, however, the parkour nickname was, by far, the preferred choice. 


\section{Defining Parkour}

Parkour has been described by scholars as an original and imaginative way to negotiate city space (Bavinton, 2007) or as unrestricted movement in places designed to restrict movement (Lamb, 20I4). According to, Chief, one of the leaders of the parkour jams, "parkour is pretty much the best thing ever." Officially, parkour is known as l'art du déplacement, or the art of displacement. The impetus for this name stems from traceurs' ability to move the body out of its usual or (what is constructed as) proper place. This displacement has traceurs turning the built environment into a series of opportunities for freedom of expression through artful forms of spatial modality. Traceurs run, jump, climb, or vault through, in and around the built environment with the goal of efficient and free flowing, always continuous, movement. A guiding maximum in parkour discourse is to find the most efficient way to get from point $A$ to point $B$ without being stopped by any obstacle in your path.

For many, parkour is both described and experienced as an act of personal freedom. The oft-quoted interview between Alex Wikinson and parkour founder, David Belle, offers Belle's sentiment of parkour as "a method for learning how to move in the world. For finding the liberty men [sic] used to have" (Newyorker.com, 2007). A sense of freedom derived from the practice of parkour is explained in its contestation of the mundane and unconscious practices of the modern world. Parkour, through this contestation, becomes a challenge to the norm, an appropriation of city space and disruption of the order of "technocapitalist space" (Atkinson, 2009: 183). Further, scholars have argued traceurs learn to challenge the production-consumption binary, which constrains urban life and restricts usage counter to those which allow capitalism to function in and define urban space (Thompson 2008; Atkinson 2009; Mould 2009; Guss 20II; Lamb 20I4). This antagonism to capitalism, research shows, is found in parkour's reinterpretation of material-spatial productions of capital flow.

The draw, to practice parkour, for many traceurs is the art form's capacity to complicate, even reject conventional, expected usages of city space (Lamb, 20I4b). This complication works to shift traceurs' experience of city life and themselves therein. Parkour's locus of transformation is from the inside out. Practitioners change their perspective as their body becomes stronger, more agile, and their vision of space expands and enriches connections with the environment. Becoming a traceur is developed through a process, a journey, toward a way of life and not simply a temporary performance of momentary subversion. The body, Foucault (1995) reminds us, is a strategic and multi-faceted site of power. As traceurs reinterpret their body they also reinterpret their relation to power, both discursively and materially, by purposefully challenging societal constraints in the interconnection of the body and architecture's participation in informing understandings of the social body.

Parkour draws inspiration from a type of military training developed by French naval officer, Georges Hébert. Hébert's training method emerged in the early $20^{\text {th }}$ century as part of his méthode naturelle (natural method). In the 1960s the French military developed obstacle courses, the Parcours du Combattant. This loosely translates to "running against" or "way of fighting" (Bavinton, 2007: 392). These training courses were based off Hébert's natural method. Raymond Belle, David Belle's father, was born in Vietnam during the war. He received an education and training from the French army, which employed many of Hébert's training philosophies. Years later, while living in France and working as a firefighter, Raymond Belle embraced Hébert's ideas of training the body. Raymond Belle 
became proficient in parcours training and the méthode naturelle. Along with his proficiency he developed an appreciation for the method's intrinsic value. Raymond Belle passed on the importance of and passion for these virtues to his son, David.

David Belle and his childhood friend, Sebatien Foucan (a key figure in the popularisation of parkour) formed the first group of traceurs, the Yamakazi. Here, Hébert's philosophy still held sway in Belle and Foucan's new art form; that is, as Atkinson (2009) notes, "immersing oneself in one's immediate physical/natural environment to gain a deep phenomenological awareness of it" (p. 172). As the members of the Yamakzi fully immersed themselves in the urban environment of Lisses, France pakour began to spread. During the late 1990s parkour's popularisation grew leaps and bounds because of its attention from the media, most notably, YouTube. Parkour's popularity continues to proliferate as the many TV commercials, Hollywood films, and YouTube videos. These media are drawn to the stylized images parkour offers.

Scholars have positioned parkour as a type of creative play, one that not only reinterprets, but challenges constraints designed into city space for the purposes of disciplining behavior (Bavinton, 2007; Geyh, 2006; Saville, 2009; Higgins, 2009; Lamb, $20 \mathrm{I} 4 \mathrm{a}$, Lamb, 20I4b). Others view parkour as a simultaneous mobile and perceptual engagement with the urban terrain. Similar studies frame parkour as a subversion of the repetition inherent in modern life, as a way of re-engaging arbitrary and often capricious habits to reclaim more purposeful actions (Sharpe, 2013). Still others have shown parkour as a form of resistance that appropriates the body from constrained experiences of, and ways of moving in, urban space (Lemos, 2010; Atkinson, 2009; Fuggle, 2008a; Thompson, 2008; Mould, 2009; Daskalaki et al, 2008). The feelings of freedom afforded by the practice of parkour, are found in how it opens new perspectives on everyday surroundings by developing highly embodied relationships with space (Ameel \& Tani, 20I2).

A common comparison is that of the traceur and the flâneur described by Benjamin (1999). The two share surface commonalities, for example, a disdain for the consumerbased cultural experience of urban space (Atkinson, 2009). What is often overlooked in what seems like an obligatory comparison is that the flâneur enjoys an untethered stroll afforded by wealth and privileged by race and gender. The flâneur is marked by wealth and education and marks the body with such. The flâneur wonders the streets searching for peculiarities that may go unnoticed by others but is more of an observer of the spectacle around him, an aloof spectator. In the vernacular of the flâneur, the traceurs is not a detached observer of this text, but a co-author. She/he seeks the actual, corporeal engagement with the physical landscape. This sort of super-engagement is not untethered to wealth, race, gender for parkour cannot erase these. JumpStart a traceur from the Indianapolis jams sheds some light on this:

"PK is about your ability to do the flow not really who you are. It's hard to define but it's not even skill level because everybody is the same and everybody is always progressing."

Put plainly, the person develops through parkour, which is in contrast to the stroll developing because of the person. 


\section{Bricolage Against Subjectivity}

Parkour helps traceurs shift interpretations of self and of space reinforced by hegemonic discourses. Within such power structures there still exist is a "degree of plurality and creativity" within urban space (de Certeau, 1984: 30). Apparatuses of production and consumption structure ways of using objects (bodies, building, products), yet these structures do not present the only ways of using objects. As the traceur jumps from building to building, over stair railings, and other obstacles designed to discipline movement, she or he is engaged in what de Certeau (1984) calls bricolage. Bricolage is the "variant of activity" in the types of operations and the roles of spaces (de Certeau, 1984: 29). In comparing the act of bricolage to reading, the bricoleur, according to de Certeau (1984), "poaches" from the dominant readings of appropriate uses of space (p. 29). Individuals take what is necessary and relevant from a text and deploy it for their own purposes. Therefore, it is no longer the passive receptivity informed by the apparatus reinforcing and concealing operational logics. Through parkour the traceur becomes the bricoleur par excellence.

Individuals making a "revolt against normative space," Borden (200I) contends, lies in their performative and representational practices wherein they re-imagine architectural space and thereby "recreate both architecture and themselves" (p. 89). Architecture and the body are both sites of power. As the traceur vaults a gate or executes a wall run overcoming the structure she or he simultaneously alters the meaning of both the body and the structure. As bodies and buildings take on meaning through spatial practice, appropriation of use, for both, is an appropriation of meaning. Edgar and Sedgwick (1999) describe bricolage as the "process by which elements are appropriated from the dominant culture, and their meaning transformed" in order to "challenge and subvert that culture" (p. 48). Parkour as a tactical act of bricolage in the strategic space of power (urban architecture) also functions as an act of bricolage against subjectivity.

Power, like parkour, has a movement of its own. Hegemonic power at work in the city must reformulate itself to maintain its ability to act on the actions afforded the traceur. Power's ability to adjust, as one traceur, Cat, describes:

"Parkour, if it continues it'll continue to have an impact. More places will put chicken wire on the rooftops. Like in France they put a mixture of broken glass and mix it with mortar to keep traceurs off the roofs. More architecture and structures will start to change based on how society sees PK. If it's spun the wrong way and becomes criminal or competitive, which is criminal, it'll have an effect on the environment that way. It already has."

This example demonstrates how power moves in order to answer its potential subversion. Power can and must "shift from one [disciplining code] to another" to subsume practices by which its efficacy is threatened (Lefebvre, 1991: 162). Recoding in the form of chicken wire barricades and glass-laden rooftops demonstrates power's need and ability to "never allow itself to be confined" so as to be able to adjust to behaviours counter to hegemonic production and maintenance (Lefebvre, 1991:162).

A hegemonic deployment of power, such as mixing broken glass and mortar, further explicates power's use of architecture to discipline individuals' perceptions of the range of available spatial practices. The result of this interplay, between power's attempt to control space and practitioners' attempts of personal freedom is what de Certeau (I984) 
refers to as a "truth value" of space (p. 99). A truth-value of space, a truth of ways of being in space, develops, as de Certeau (1984) explains, individuals' "epistemic modalities;" how subjects come to know and interpret the ensemble of possibilities for spatial the practices (p. 99). The construction of an epistemic modality - knowing who I am based on where I am or knowing where to go based on where I can go - highlights the importance of an epistemology of doing with regard to understanding parkour as this approach is centred on knowledge being locational, situational, and positional. As a kind of pedagogy of space, epistemic modalities become so normalised they reduce and limit the creativity and improvisation needed for the production of more emancipatory urban spaces.

Parkour is a continuous change in spatial location and therefore is a constant change in traceurs' relation to space. Parkour requires an expansion of traceurs' epistemic modalities. As a traceur my subjectivity, and my power to act (agency), are informed by my spatial location and the produced meaning (representation), of the space. My body takes on different meaning and thus enacts different modalities in the overlapping of myriad spaces. These spaces, too, are not demarcated as little islands of space but also reflect meaning and produce representations of each other. Further, these spaces not only reflect my subjectivity they also re-inscribe my relation to the architecture in my occupancy or absence of those spaces. I learn, or know, how to move and where I can move based on who and where I am in relation to architectural space.

Traceurs develop expanded and more nuanced epistemic modalities. Parkour's alternative perception of architecture challenges attempts to homogenise experiences of city space and as a result homogenise spatial practices. As Par-ker comments:

"5 or 6 people see the exact same thing but you see it differently. Your perceptions are based on ability... based on your level. So an obstacle, like a building, is about your perception. So with parkour, I guess I can adapt to situations and be different than most people."

This progress however, is still tethered to a spatial order, which "organizes an ensemble of possibilities and interdictions," for example, possible places in which one can move or a wall that prevents one from going further (de Certeau, 1984: 98). As one traceur explains:

"the structure is the move. Location dictates your movement. Location in terms of where you are or where you're from will influence the type of flow and the techniques they throw" (Cat).

Cat continues, stating:

"If structures are tightly knitted the flow is different. If its 50 or 60 feet apart you develop more cardio whereas if you're doing short jumps you have a tighter flow and its based off your terrain and your vision of it. Indiana: not a good place for parkour. It's real spread out and around here you have to seek places out. We'll check out a place and the structure isn't strong enough to support you. But in the U.K. the architecture is built better and will hold you. Here you jump up and reach out to get a hold and the brick comes off in your hand. It doesn't allow people to experience PK in the U.S. like they do overseas because of so much space between us. You have to drive for a while to find something you can play on." 
The traceur's acts of bricolage are situational, spatial, and contextual and in many ways dictated by the built environment. Engaging architecture through bricolent activity improves traceurs' epistemic modalities.

The spatial order, however, reciprocally informs which obstacles are repositioned as opportunities. Different obstacles lend themselves to a differently developed traceur. Johnny, one of Cat's friends, further explains,

"This gives people different development and lends itself to different training and a different training mind set. You develop based on what's around you and that develops a certain mindset. It's like why everybody wears different clothes in different areas. So, if you're used to being in flat spaces you're going to do more running because you're trying to fill the space with movement, but, if you're in a tight knit space it allows you to do more kongs, monkeys, and jumps. That develops your body different and your vision too."

Here we see the conception of freer engagement with space, expanding epistemic modalities, is produced dialectically with the space in which one is enmeshed. Parkour in a more dense urban space develops the traceur's spatial sensibilities differently than parkour in a less dense area, in this example, Indianapolis.

The traceur's body, too, plays a significant role in how she or he develops a vision of the line in the built environment.

"Different body types" one traceur reveals, "dictate the moves" (Collin).

He further states:

"Someone who's 6'4" can't take the path the same way as somebody who's 5'2" so a different body type has a different attack method. For example, taller people a lot of the time might take a higher line" (Collin).

The physicality of one's body informs how she or he uses architecture in parkour. Simultaneously the architecture informs how she or he uses the body. The series of moves one conducts is "based on your body...it causes you to be more self-aware because you have to be aware of your body like you're using it to solve a problem" (Amy). These comments reveal the intricate balance between the body and architecture as each plays a central role not only in the traceur's development but also in her or his conceptualising the body's role in epistemic modalities.

In my development as a traceur I have found that perhaps parkour's greatest act of freedom is in the ways that it redefines and repositions social relations. Parkour reframes the building or boundary in which one self-checks her or his identity. Buildings become opportunities to act and a tool of traceur agency. This reframing, for many traceurs, allows parkour to be a practice, which produces themselves and others as a community. TooAmy, a leader of many of the parkour jams, positions the development of traceurs as a development in a

"family...it [parkour] is very social and supportive and everyone supports you in your progress."

Another traceur, Billy, buttresses this feeling commenting:

"parkour has really made me open to different people and different ideas. Parkour is about gathering and moving and helping each of get better." 
Reframing the viewing mechanism (architecture) into an opportunity to develop family and become open to new people and different ideas creates urban architecture as a potential space of support and new social relationships. Jamy, an experienced traceur, finds this coming together to be emancipatory:

"people now days have lots of social pressure and people don't do things because of judgment... but with parkour it's like you're free of all that, it's like I fit in because I'm able to adapt and get better."

In being free of social pressure, traceurs challenge the mirrored image of the 'Other' as they also challenge their prescribed reflection.

Architecture as a viewing mechanism (re)produces self and Other, however, parkour perturbs this effect on the relationship between architecture and the body by reproducing spaces of equality, appreciation, and community. As traceurs come together they produce a new set of social relationships that architecture tries to condense. It is through parkour that traceurs create emancipatory social bonds. As Cat explains,

"the travel is the bond."

The ability to appropriate spaces and social relationships toward more communal and equal sensibilities provides a sense of agency. This sense of acceptance and community is reiterated by Cat who states:

"parkour is something everyone can do. You look at it and think all they're doing is running and climbing and jumping. I can run and jump and climb. That's all. Keep it that simple."

TooAmy agrees. She states,

"parkour is non-judgment and non-judgment builds trust. So, people can communicate more freely not only in parkour but in other things in life as well."

In expanding the nature of social relationships and centring them on parkour, this art has value outside of corporeal connection of body and building. Parkour helps traceurs reshape the understanding of self and others and facilitates the (re)production of more emancipated spatial practices and relationships.

\section{Operational Logic and the Optical Knowledge of Space}

For de Certeau (1984), the rationalising of how we use space, through discourse and practice, becomes hidden as operational logics. Operational logics are manifested through "ways of using dictated by a dominant economic order" (de Certeau, 1984: xiii).

Appropriate ways of using the objects of place and of using the body in space are imposed by relations of power, always social, who determine the "types of operations and the role of space" (de Certeau, 1984: 30). For de Certeau (1984) the types of operations consist of strategies and tactics, or different ways of operating, which he describes as "instructions for use" (p. 30). Strategies are able to "produce, tabulate, and impose these spaces" informed by the operational logics wherein they take place (de Certeau, 1984: 30). A strategy is a rationalisation seeking 'first of all to distinguish its 'own' place...the place of its own power and will, from an 'environment"' (de Certeau, 1984: 36).

Architecture can act as a mirror to our subjectivity in a way that creates what de Certeau (1984) calls an "optical knowledge" of urban space (p. 93). In other words, individuals perceive power's representation in architecture and their access or denial to space and 
the range of available uses therein. Over time, traceurs acquire a parkour vision, which challenges the optical knowledge prescribed in architecture. As TooAmy eloquently describes:

"I compare it to taking a painting class. You have to mix all the colours and shades and if you do it long enough you start to see all that in your environment. The more you practice, the more you do it [painting], and the more you know how to do it, you develop it in your mind. Everywhere you go you see it. Like the painting class, you're learning that ability to notice opportunity in your environment. From PK you learn how to see the obstacles differently."

Once you commit to the act of parkour and you grab the building, you feel something has changed. You have, perhaps, felt concrete before but not in the sense of doing something out of place, like you might get caught in some violation. In one of our jams I described this as walking into your roommate's bedroom when she/he is not home. The space has not changed but you become acutely aware of its rules even if those are not formally stated.

This is, perhaps, the key insight offered by parkour: this vulgar gripping (quite literally) of the power of discourse, and at once, in the act of bricolage, fore fronting the operational logic - the expected ways of using space per the dominant economic order. In parkour,

"everyone has a different perception of their line. So parkour teaches you a vision of the obstacles and how to see your line" (Par-ker).

This constitutes an optical knowledge of their own which leads to different spatial engagements. Traceurs challenge a normative optical knowledge, a visual representation of power, through corporeal connection to architecture, an embodied agency. When we vault a stairway, for example, it has no power in its physicality. Power is produced in the stairway through use. The structure has the power to prescribe but not to determine as architecture "reproduces itself within those who use the space... within their lived experience" (Lefebvre, 1991: 137). Traceurs, then, redefine architectural space through a redefinition of appropriate use. As one traceur explains,

"normal society is taught that a wall is supposed to keep you out, unless you're criminally minded. People will see it as a barrier. With parkour you start to see walls that you can look at differently, it's not a barrier anymore" (Chief).

Normal society, as he states, creates ways of operating or instructions for use, for example, the wall being designed to keep you out.

In the parkour flow the architecture and the body are redefined not in their physicality but within their connection. Johnny indirectly explains the traceur as bricoleur:

"I think architecture has limited us. We learned in my psych class it's called functional fixedness where you see the object for what it's supposed to do and when you do something different with it you change its purpose. In parkour you are changing the purpose of the obstacle because you're doing something different than its purpose like a gate or wall.”

The traceur as bricoleur at once recodifies the meaning of both body and the obstacle. The functional fixedness of the gate or wall, as he explains above, has a meaning as a barrier. That meaning is produced through use as a spatial practice. Walking through the 
gate for those who have access as well as keeping out for those who do not, those uses re-inscribe or (re)produce the meaning of the gate and the bodies conforming use to the constructed meaning.

\section{Conclusion}

The body and architecture are produced in and among the material relations producing urban space. One might say that the parkour flow is produced within a flow: capital flow. Bodies and buildings have a material existence or physicality. Each exists as producer and production of space. The body and the building take on meaning through the spatial practices that constitute one another. Their meaning is reflected and internalised in their relationship. Buildings reflect meaning onto bodies and in this relationship meaning rebounds, reflects, and constitutes subject and space for these cannot be understood as mutually exclusive.

The relationships and the meanings produced therein are in constant dialectic struggle with the lived practices of individuals in social relations inherently imbued with power. Parkour can be used to understand the relationship between architecture and the body as it engages the spatial practices that produce meaning, bodies, and buildings. Through its very exteriority of appropriate use of the body and of architecture, the practice of parkour lends insight into how each produce one another through discursive and material practices. This exteriority positions parkour as an act of freedom, but also as an emancipatory way of being, in urban architectural space.

Thus, parkour is not only a tactical use of strategic architectural space through bricolent appropriation but is at once a tactical (mis)use of my body as a strategic site of power. As I develop as traceur-tactician I develop the skills to make tactical (mis)use of my body. Through the parkour flow, with each successive bricolent maneuver over one obstacle to the next, I am simultaneously enacting bricolage against my subjectivity by manipulating or recasting constraining discourses that constitute my body. Parkour, in its expansion of dominant discourses, can be seen as an action on the actions of power. Traceurs, through freer engagement of architectural space (and their bodies) do not liberate themselves from power but alter, upset, and challenge its ability to define them.

\section{References}

Ameel, L., \& Tani, S. (2012). Everyday aesthetics in action: Parkour eyes and the beauty of concrete walls. Emotion, Space, and Society, 5(3), 164-I73.

Amin, A. (2008). Collective culture and urban public space. City, I 2(I), 5-24.

Atkinson, M. (2009). Parkour, anarcho-environmentalism, and poiesis. Journal of Sport \& Social Issues, 33(2), 169-194.

Bavinton, N. (2007). From obstacle to opportunity: Parkour, leisure, and the reinterpretation of constraints. Annals of Leisure Research, 10(3/4), 39I-4I2.

Benjamin, W. (1999). The arcades project. Cambridge: Harvard University Press.

Borden, I. (200I). Skateboarding, space and the city: Architecture and the body. Oxford: Berg.

Colomina, B. (1996). Privacy and publicity: Modern architecture as mass media. Cambridge: MIT Press.

Daskalaki, M., Stara, A., \& Imas, M. (2008). The 'parkour organization': Inhabitation of corporate spaces, Culture and Organization, I 4(I), 49-64.

de Certeau, M. (1984). The practice of everyday life. (Rendall, S. Trans.). Berkeley: University of California Press. 
Drucker, S., \& Gumpert, G. (1991). Public space and communication: The zoning of public interaction. Communication Theory, I (4), 294-3I0.

Edgar, A., \& Sedgwick, P. (eds) (1999). Key concepts in cultural theory. New York: Routledge. Foucault, M. (1995). Discipline and punish: The birth of the prison. New York: Random House.

Fuggle, S. (2008a). Discourses of subversion: The ethics and aesthetics of capoeira and parkour. Dance Research, 26(2), 204-222.

Fuggle, S. (2008b). Le parkour: Reading or writing the city? In Lindley, E., \& M. McMahon (eds.), Rhythms: Essays in French literature, thought, and culture (159-170). Oxford: Peter Lang.

Gajjala, R. \& Altman, M. (2006). Producing cyber-selves through technospatial praxis: Studying through doing. In P. Liamputtong (Ed.), Health research in cyberspace (I-I8). Nova Science Publishers.

Gajjala, R., Rybas, N., \& Altman, M. (2007). Epistemologies of doing: E-merging selves online. Feminist Media Studies, 7(2), 209-2I3.

Geyh, P. (2006). Urban free flow: A poetics of parkour. M/C Journal, 9(3). Retrieved from http://journal.media-culture.org.au/0607/06-geyh.php

Gieryn, T. (2002). What building do. Theory and Society, 3 I (I), 35-74.

Guss, N. (20II). Parkour and the multitude: Politics of a dangerous art. French Cultural Studies, 22(I), 73-85.

Higgins, J. (2009). The revitalization of space: Freestyle parkour and its audiences. Theatre Symposium, 17, 113-123.

Hillier, B., Burdett, R., Peponis, J., \& Penn, A. (1987). Creating life: Or does architecture determine anything? Architecture \& Comportement/ Architecture \& Behaviour, 3(3), 233-250.

Kidder, J. L. (2012). Parkour, the affective appropriation of urban space, and the real/virtual dialectic. City \& Community, II (3), 229-253.

Lamb, M. D. (20/4)a. Misuse of the monument: The art of parkour and the discursive limits of a disciplinary architecture. Journal of Urban Cultural Studies, I(I), I07-I26.

Lamb, M. D. (2014)b. Self and the city: Parkour, architecture, and the interstices of the 'knowable' city. Liminalities: A Journal of Performance Studies, I0(2), I-20.

Lefebvre, H. (199I). The production of space. (D. Nicholson-Smith, Trans.). Oxford: Blackwell.

Lemos, A. (2010). Post-mass media functions, locative media, and informational territories: New ways of thinking about territory, place, and mobility in contemporary society. Space and Culture, 13(4), 403-420.

Lloyd, J. (2003). Airport technology, travel, and consumption. Space and Culture, 6(2), 93-109.

Mitchell, D. The end of public space? People's park, definitions of the public, and democracy. Annals of the Association of American Geographers, 85(I), 108-I33.

Mould, O. (2009). Parkour, the city, the event. Environment and Planning D: Society and Space, 27(4), 738-750.

Ortuzar, J. (2009). Parkour or l'art du deplacement: A kinetic urban utopia. TDR: The Drama Review, 53(3), 54-66.

Saville, S. (2009). Playing with fear: Parkour and the mobility of emotion. Social \& Cultural Geography, 9(8), 891-914.

Sharpe, S. (2013). The aesthetics of urban movement: Habits, mobility, and resistance. Geographical Research, 5I(2), I66-I72.

Thomas, J. (1993). Doing critical ethnography. Newbury Park: Sage.

Thompson, D. (2008). Jump city: Parkour and the traces. South Atlantic Quarterly, 107(2), 25I-263.

Wilkinson, A. (2007). No obstacles: Navigating the world by leaps and bounds. The New Yorker. Retrieved from http://www.newyorker.com/reporting/2007/04/I6/0704I6fa_fact_wilkinson

Witfeld, J., Gerling, I. E., \& Pach, A. (20I I). The ultimate parkour \& freerunning book: Discover your possibilities. (H. Ross, Trans.). Maidenhead: Meyer \& Meyer Sport. 